
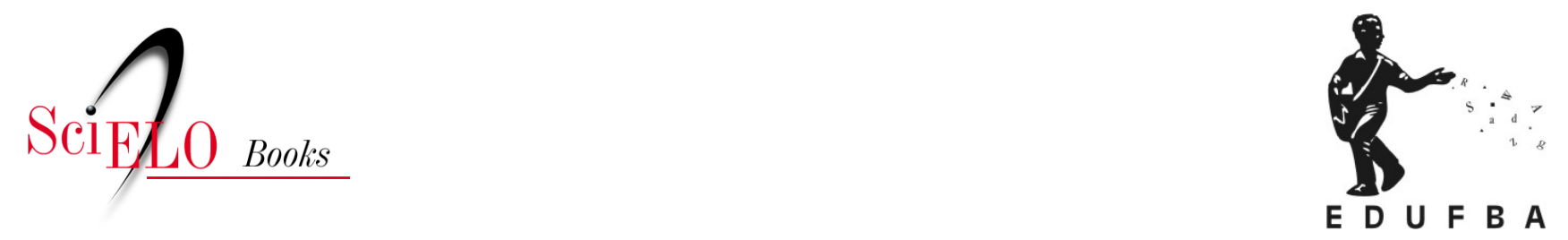

\title{
Atenção primária à saúde reflexões sobre a política a partir da prática de pesquisa
}

\author{
Maria Guadalupe Medina \\ Rosana Aquino \\ Ana Luiza Queiroz Vilasbôas \\ Cristiane Abdon Nunes \\ Nília Maria de Brito Lima Prado
}

\section{SciELO Books / SciELO Livros / SciELO Libros}

MEDINA, M.G., AQUINO, R., VILABÔAS, A.L.Q., NUNES, C.A., and PRADO, N.M.B.L. Atenção primária à saúde: reflexões sobre a política a partir da prática de pesquisa. In: TEIXEIRA, C.F., comp.

Observatório de análise política em saúde: abordagens, objetos e investigações [online]. Salvador: EDUFBA, 2016, pp. 227-265. ISBN 978-85-232-2021-1.

https://doi.org/10.7476/9788523220211.0008.



All the contents of this work, except where otherwise noted, is licensed under a Creative Commons Attribution 4.0 International license.

Todo o conteúdo deste trabalho, exceto quando houver ressalva, é publicado sob a licença Creative Commons Atribição 4.0. 
Maria Guadalupe Medina, Rosana Aquino, Ana Luiza Queiroz Vilasbôas, Cristiane Abdon Nunes e Nília Maria de Brito Lima Prado

\section{ATENÇÃO PRIMÁRIA À SAÚDE reflexões sobre a política a partir da prática de pesquisa}

\section{Introdução}

A Atenção Primária à Saúde (APS) tem sido prioridade das políticas públicas nas últimas décadas no Brasil e no mundo. Em diversos movimentos de reforma dos sistemas de saúde, atribui-se à APS um papel central na mudança dos modelos de atenção e das práticas sanitárias, enfatizando, especialmente, que esse nível de organização do sistema é lócus privilegiado para a implementação de ações de promoção da saúde e de articulação intersetorial. (AQUINO et al., 2014)

O eixo "Estudos e Pesquisas em Atenção Primária e Promoção da Saúde” - do Observatório de Análise Política em Saúde (OAPS) toma como seu objeto de investigação e análise as políticas de atenção primária e promoção da saúde implementadas no Brasil nos últimos anos, vale dizer, as ações do governo brasileiro frente às necessidades de saúde da população, que se expressam diretamente em intervenções operadas por sistemas locais de saúde, especialmente pelo trabalho dos serviços de atenção primária. 
Sistematizar a experiência desse grupo de pesquisa é um empreendimento de natureza complexa e exige, de pronto, que se façam algumas ressalvas, seja para não criar no leitor expectativas que não serão atendidas neste texto, seja para esclarecer os pontos de ancoragem em que as autoras se sustentam, ao mesmo tempo limitantes do recorte adotado e das opções de abordagem do tema, que são inúmeras. Ressaltamos, desde já, que nossa reflexão circunscreve-se ao objeto APS, não sendo o propósito deste capítulo aprofundar as questões específicas das políticas de promoção da saúde.

Reconhece-se que há diferentes análises possíveis sobre a(s) política(s) de APS, por inúmeras razões. Em primeiro lugar, porque a compreensão sobre o objeto "atenção primária à saúde" é distinta em função da posição em que o pesquisador se coloca. Há, pois, que iniciar a análise produzindo uma reflexão sobre o próprio objeto, indagando de que atenção primária se fala, que proposições têm sido formuladas ao longo do tempo e em que contextos. Essa preocupação pode ser considerada como recurso metodológico se assumirmos, como Bourdieu (1999), que a primeira ação do pesquisador é pôr em questão seu próprio objeto, compreender a genética dos conceitos, ou seja, sua construção sócio-histórica. Trata-se aqui de fazer aflorar uma dúvida radical, necessária à construção dos objetos científicos, rompendo com " $[. .$.$] representações partilhadas por todos, quer se$ trate de simples lugares comum da existência vulgar, quer se trate de representações oficiais frequentemente inscritas nas instituições”. (BOURDIEU, 1999, p. 34) O primeiro tópico deste texto, portanto, buscará de forma breve, problematizar a APS como objeto de investigação, apresentando algumas concepções adotadas em tempos e conjunturas distintos e alguns recortes possíveis para a sua análise.

Um segundo esclarecimento ao leitor refere-se à dupla dimensão de análise da APS presente nos estudos desenvolvidos pelo eixo "política e prática”. Embora essas duas dimensões necessariamente se articulem, uma vez que qualquer política exige uma tradução operacional enquanto prática, e que a organização de práticas (assistenciais e gerenciais) é também determinada pela política, a análise de tais di- 
mensões é distinta. Isso significa que há recortes teóricos e percursos metodológicos particulares a cada uma dessas dimensões. Esse aspecto será explorado, especialmente, no segundo tópico deste capítulo.

Não restringimos a análise ao escopo da política por duas razões: primeiro, porque a grande maioria dos estudos sobre a atenção primária no Brasil e no mundo circunscreve aspectos específicos das práticas desenvolvidas no âmbito da APS; segundo, porque uma questão central na análise da política de APS é compreender os limites e possibilidades de mudança de modelos de atenção à saúde, o que implica a análise das práticas. A incipiência de uma abordagem científica na análise política da política de APS no Brasil é uma limitação concreta com que temos de lidar neste trabalho.

Ao elencar como política as intervenções implementadas no âmbito do sistema de saúde (senso amplo), não se ignora que a análise do espaço da política deve iluminar, também, as omissões do Estado frente às necessidades de saúde da população, como bem assinala Paim e Teixeira(2006) na sua formulação original do conceito de política de saúde. Nesse sentido, a análise da produção científica desenvolvida neste capítulo pretende destacar elementos importantes da (não) direcionalidade da política de APS na construção de sistemas universais de saúde.

Por fim, concluímos o capítulo apontando alguns desafios colocados hoje para a investigação de APS no país. Esperamos que este capítulo possa contribuir com a reflexão sobre os rumos da saúde no Brasil, especialmente nesse cenário marcado por tantas incertezas.

\section{A APS como objeto de investigação: problemática e recortes possíveis}

Qual o objeto da pesquisa em atenção primária em saúde? Em 2003, um editorial publicado no jornal científico Lancet, "Is primary-care research a lost cause?", com o propósito de discutir os desdobramentos de uma conferência sobre pesquisa em APS da Organização Mundial de Médicos de Família (WONCA EUROPA, 
2002), questionou a pertinência da especificidade desse tema como objeto de pesquisa. O editorialista defendeu a ideia de que, se existisse um foco diferenciado de investigação nessa área, este deveria ser o estudo das relações entre doença e família, dadas as profundas transformações e diversidade de modelos familiares nas sociedades modernas, a proximidade da APS a esses contextos e o impacto dessas mudanças nos processos de adoecimento. (DOUGLAS, 2003) Esse pronunciamento suscitou um grande debate entre os investigadores que reconheciam a importância daquela conferência internacional, que cunhou uma definição europeia de APS e medicina de família (general practice/family medicine), para o delineamento de políticas e estratégias de fortalecimento da capacidade investigativa em APS naquele continente. (DOUGLAS, 2003; HOWE, 2003) Em defesa da relevância da pesquisa em contextos de APS e da sua diferenciação da pesquisa clínica "tradicional", foram levantados argumentos contrários à restrição do foco ao estudo das relações entre família e adoecimento, uma proposta ultrapassada, com referência aos mode230 los de APS da década de 1970, e distante dos desafios atuais para organizar sistemas de saúde baseados na APS. (DELANEY, 2004)

Nessa arena de discussões, que permanece atual, prevalecem não apenas questões epistemológicas e metodológicas, como outros aspectos que contribuem para conformar o campo da pesquisa em saúde, a exemplo das discussões sobre as relações entre a política editorial dos periódicos científicos e as lógicas de financiamento da pesquisa em saúde que seriam determinantes da baixa produção em pesquisa em APS. (DELANEY, 2004) Fortemente subsidiada pela indústria farmacêutica, a pesquisa clínica tem um padrão de fomento muito diverso ao da pesquisa em APS que não só depende quase que exclusivamente de financiamento público, como também tem uma participação minoritária no conjunto dos recursos públicos destinados a esse fim. Mesmo em países com APS forte, como é o caso da Austrália, Holanda, Nova Zelândia e no Reino Unido, o percentual do financiamento da pesquisa na área oscilava em torno de $5 \%$ no início dos anos 2000. (GROL; JONES, 2000) 
Entendendo que o foco da pesquisa é a própria APS, suas práticas e modelos de organização, vários pesquisadores defendem a necessidade de desenvolvimento de modelos conceituais e metodologias em APS para produção de evidências da efetividade e custo-efetividade dos cuidados primários na resolução de problemas de saúde, frente a outros modelos de organização dos sistemas de saúde. (MACINKO et al., 2004; NEDEL et al., 2011; VIACAVA et al., 2004)

Além disso, o conhecimento obtido pelas pesquisas produzidas por especialistas e em contextos hospitalares tem, muitas vezes, pouca aplicabilidade no âmbito da atenção primária à saúde. As condições e problemas de saúde manejados na APS são de frequência e natureza diversas daquelas que são comuns aos especialistas, assim como é diferenciado o cuidado em saúde no âmbito comunitário, onde se desenvolvem as ações de APS, intervenções complexas, que buscam abarcar não apenas o cuidado com os doentes, mas a prevenção de riscos e agravos e a promoção da saúde. (STARFIELD, 2002)

Finalmente, são necessárias investigações que possam subsidiar a reorganização e avaliação desse nível de atenção e das suas inter-relações com os demais níveis do sistema de saúde, com outros setores governamentais fora do setor saúde, com organismos não governamentais e organizações comunitárias.

A produção científica nesse campo deve contemplar, por um lado, modelos teórico-lógicos que explicitem um conjunto de princípios, dimensões e atributos com vistas à construção e operacionalização de conceitos de APS que possam ter aplicabilidade universal; e por outro lado, abordagens metodológicas que permitam apreender as formas concretas e diversas de organização da APS nos diferentes contextos, dado que sua implementação é contexto-dependente. (MEDINA; HARTZ, 2009)

Em que pese o crescimento da produção na área nos últimos 20 anos, podemos dizer que há um aparente paradoxo entre a produção de diversos documentos de posição de organismos internacionais, a exemplo da World Health Organization (WHO) e Organização Pan-americana de Saúde (OPAS), na defesa de reforma dos sistemas 
nacionais de saúde para sistemas centrados em APS, e o não desenvolvimento equivalente da capacidade de pesquisa sobre o tema para embasar e subsidiar as reformas propostas. Assim, embora exista um consenso internacional sobre a efetividade de sistemas de saúde orientados pela APS, isso contrasta com a falta de prioridade em pesquisa sobre o tema (HUMMERS-PRADIER et al., 2009; MCAVOY, 2005) e a ausência de centralidade das questões de investigação na problemática dos processos de trabalho e de organização da APS na sua relação com o sistema de saúde.

Para a construção do objeto APS, se tomarmos como ponto de partida as definições disponíveis em documentos normativos, como a Política Nacional de Atenção Básica (PNAB) (BRASIL, 2012), o documento de posição da Panamericana de Salud Organización (, 2007), a definição da Wonca Europa (2002) ou de autores clássicos, como Barbara Starfield (1979), concluímos que estamos diante de um objeto multifacetado, com múltiplas dimensões e categorias(Quadro 1), que dificilmente poderiam ser apreendidas em uma única pesquisa, mas, ao contrário, exigem uma diversidade de abordagens teórico-conceituais e metodológicas. Além disso, por ser espaço de desenvolvimento de práticas e implementação de programas ou políticas, muitas pesquisas não investigam a APS enquanto objeto, mas apenas como cenário, fazendo-se necessário distinguir pesquisa "em" de pesquisa "na” APS. 












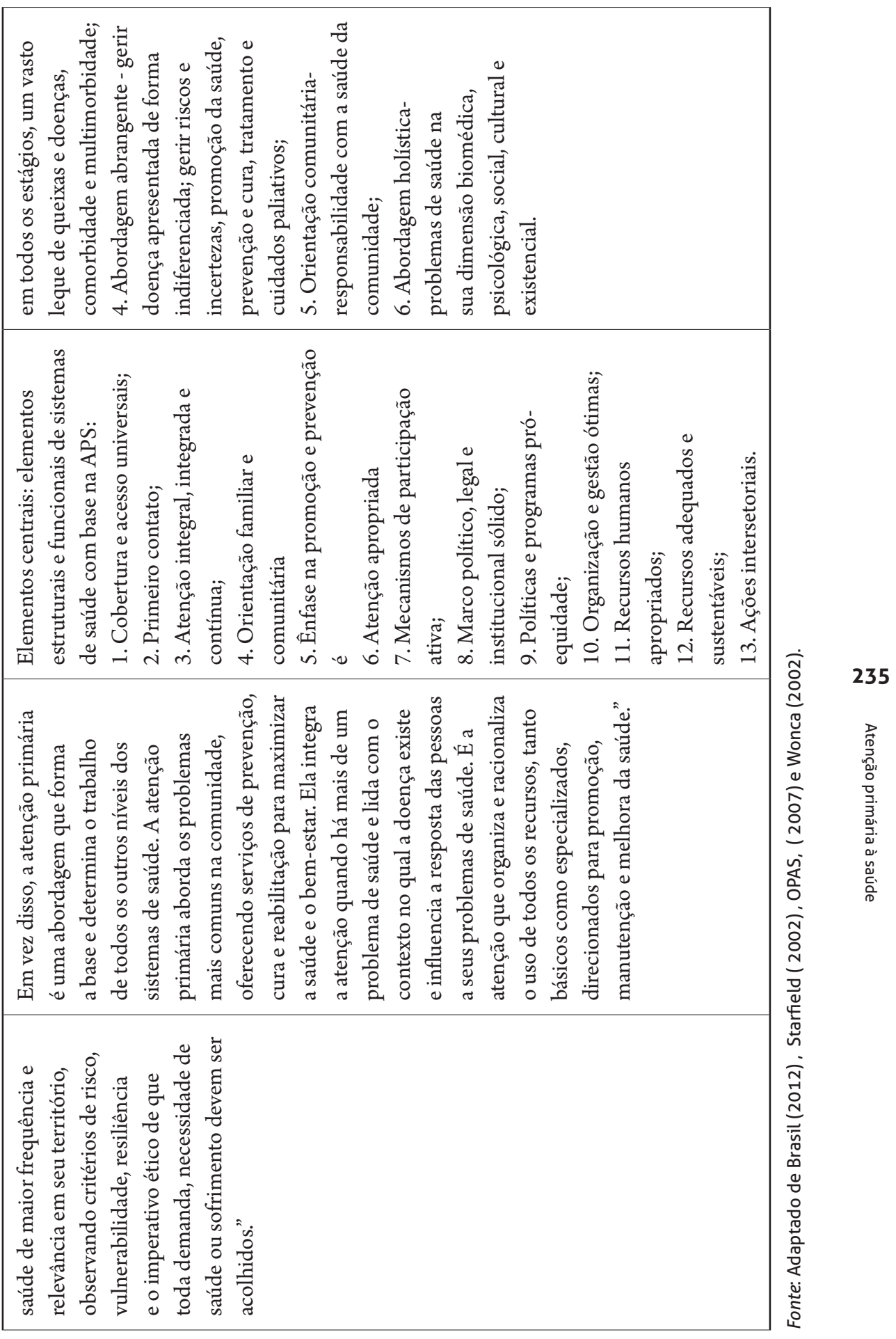


Podemos destacar várias questões-chaves de investigação:

- Problemas de saúde e seus determinantes. A natureza dos problemas de saúde no contexto da APS é bastante diversa da natureza dos problemas manejados nos demais níveis do sistema de saúde. Primeiro, porque para desenvolver ações de promoção da saúde e prevenção de doenças, faz-se necessário ampliar o olhar e o elenco de questóes e problemas, para além das doenças na sua expressão individual. Segundo, porque mesmo sendo doenças ou agravos, estes se apresentam em contextos de baixa incidência e prevalência, o que coloca questóes específicas que dificultam a sua identificação, relacionados a duração e severidade das doenças. Terceiro, são diversos os fatores que influenciam a decisão do usuário em consultar e não consultar o serviço e, na maioria das vezes, os problemas de saúde que levam os usuários a buscar os serviços de APS, ao invés de doenças bem definidas, são sintomas indiferenciados, multifatoriais em origem, diversos em espectro, frequentemente de curta duração e muitos de causa desconhecida. Assim, podem ser destacadas algumas questóes acerca dos padróes e significado clínico do adoecimento, que são específicas dos contextos de APS. (STARFIELD, 2002)

+ Concepções e modelos de APS. Diversas são as características e dimensões centrais da APS que demandam investigações teórico-conceituais e estudos avaliativos. Como ordenadora do sistema de saúde, a APS deve constituir-se no primeiro contato dos usuários com os serviços, na maioria das condições e problemas de saúde, garantindo acesso universal, e oferecer e coordenar a atenção integral, integrada e continuada a indivíduos, famílias em seus territórios de atuação. Além disso, para romper com modelos de atenção fragmentados, preconiza-se a orientação familiar e comunitária, a ênfase na promoção da saúde e prevenção de agravos, o desenvolvimento de ações intersetoriais e a 
promoção de mecanismos de participação ativa. (AQUINO et al., 2014; RASELLA et al., 2013, 2014)

- Práticas e processos de trabalho das equipes multiprofissionais de APS. A necessidade de abarcar intervenções de promoção da saúde, prevenção e cuidado exige competências específicas que permitam que os profissionais lidem com a incerteza e complexidade desses problemas, estabeleçam relaçôes de cooperação entre si, priorizando o trabalho multiprofissional, e desenvolvam relaçôes de corresponsabilidade, que favoreçam a autonomia dos usuários. Destaca-se, ainda, que o manejo de sintomas indiferenciados apresenta questões específicas do âmbito da APS: o tratamento, muitas vezes, independe do diagnóstico, estando centrado nos sintomas e queixas dos usuários; é preciso estabelecer o valor preditivo dos sintomas de alta frequência na população para identificação de doenças graves de baixa incidência - como dor de cabeça/tumor de cérebro; é preciso identificar condições onde intervenções precoces podem ser benéficas sem resultar em "medicalização" excessiva; e, finalmente, existem condições frequentes cujo conhecimento acumulado, através de estudos em serviços especializados e hospitalares, tem pouco aplicabilidade em contexto de APS (epidemiologia da dor crônica baseado em casos graves que representam um percentual pequeno). Assim, são colocadas novas e diversas questóes de pesquisa, que possam abarcar essas dimensões sobre o cuidado em saúde. (CARVALHO et al., 2015; PEDUZZI, 2003; SOUZA, 2015)

- Modelos de gestão da APS.As questões de investigação nessa área referem-se desde o marco político, legal e institucional que rege os sistemas de saúde, as formas de organização e gestão dos serviços, até os mecanismos que promovem a incorporação de pessoal e tecnologias, bem como a formação de profissionais. (MACINKO et al., 2004; SPEDO; TANAKA; PINTO, 2009) 
No Brasil, grande parte das investigações desenvolvidas na última década centrou atenção na Estratégia Saúde da Família (ESF), eleita como política de reorganização da APS no país. Assim, a partir dos anos 2000, tem-se observado o aumento do número de estudos de caso por todo o país, estudos de abrangência nacional com a utilização de dados secundários e, mais recentemente, grandes inquéritos com centralidade nessa política.

Estudos de caso têm evidenciado inovações organizacionais da ESF em aspectos como abordagem territorial, trabalho em equipes multiprofissionais e articulação de ações preventivas, de promoção e cuidado em saúde, mas dificuldades relativas à participação social, e implantação da APS em zonas rurais (MEDINA; HARTZ, 2009; NUNES, 2011), bem como incipiência na realização ações de planejamento e vigilância da saúde. (SANTANA; AQUINO; MEDINA 2012; VILASBÔAS; PAIM, 2008)

Estudos comparativos têm sido bastante utilizados para investigar diferenças entre a ESF e o modelo tradicional de APS centrado em Unidades Básicas de Saúde (UBS) e alguns resultados apontam para melhor desempenho da ESF em ações programáticas (TOMASI et al., 2015), cuidado integral, visitas domiciliares e relação com a comunidade, principalmente em regiões mais pobres e com populações mais vulneráveis. (FACCHINI et al., 2006; PICCINI et al., 2006, TOMASI et al., 2011) Recente inquérito nacional sobre as práticas dos agentes comunitários de saúde, conduzido por grupos de pesquisa do OAPS, demonstrou consolidação de ações essenciais de saúde da mulher e da criança, embora inovações nas práticas de promoção e de vigilância tenham sido incipientes. (NUNES et al., 2015)

Importantes estudos de abrangência nacional desenvolvidos com dados secundários, a partir dos sistemas de informação em saúde, têm demonstrado impacto da ESF na mortalidade infantil e de menores de cincoanos (AQUINO; OLIVEIRA; BARRETO, 2008; MACINKO; ALMEIDA, 2006; MACINKO et al., 2007), destacando-se, também, a redução da mortalidade por diarreia e pneumonia (RASELLA; AQUINO; BARRETO, 2010) e redução das hospita- 
lizações por condições sensíveis à atenção primária. (DOURADO et al., 2011; MACIEL et al., 2014; PEREIRA SILVA; NETO, 2014; RASELLA et al., 2013; RODRIGUES-BASTOS et al., 2014; ROSANO et al., 2012)

No âmbito do OAPS de, algumas investigações se encontram em curso no eixo "Estudos em Atenção Primária e Promoção da Saúde”, sendo que algumas delas já foram concluídas. A seguir são apresentadas questões gerais de investigação sobre as quais o grupo tem se debruçado:

+ Quais são os modelos de APS adotados no país?

- As políticas de APS têm favorecido um modelo de atenção que prioriza a promoção da saúde e favorece a integralidade do cuidado?

+ A APS contribui para promover a equidade em saúde?

- O processo de implementação do Sistema Único de Saúde (SUS) aponta para o fortalecimento e centralidade da APS na organização do sistema de saúde?

- Que inovações organizacionais tem sido implementadas no âmbito da APS?

- A APS tem contribuído para promover a saúde na esfera individual e nas coletividades humanas?

- Qual o desempenho da APS no cumprimento de suas funções essenciais?

No Quadro 2, estão sistematizados os estudos concluídos e em andamento por referência a essas questões gerais. 


\begin{tabular}{|c|c|c|c|c|}
\hline  & & 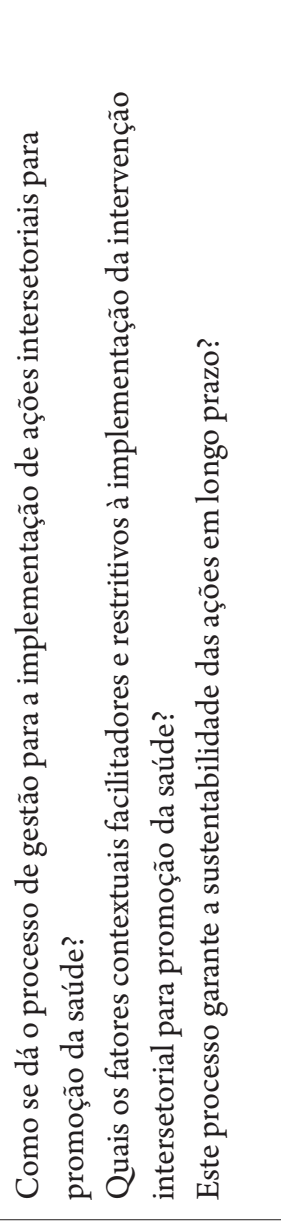 &  & 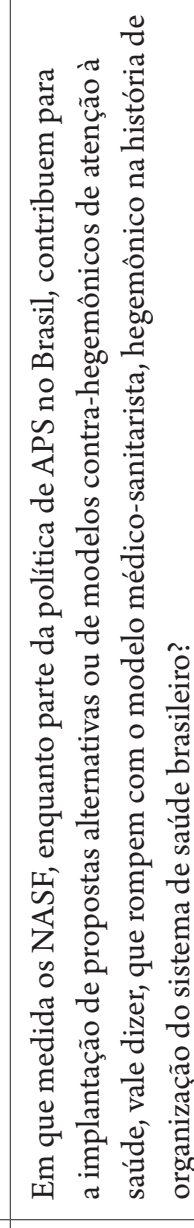 \\
\hline 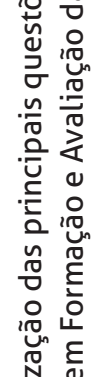 & 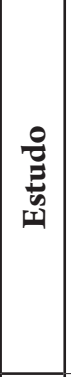 &  &  & 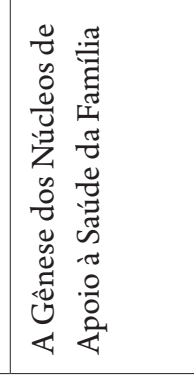 \\
\hline 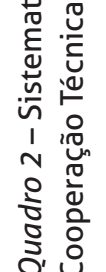 &  & \multicolumn{3}{|c|}{ 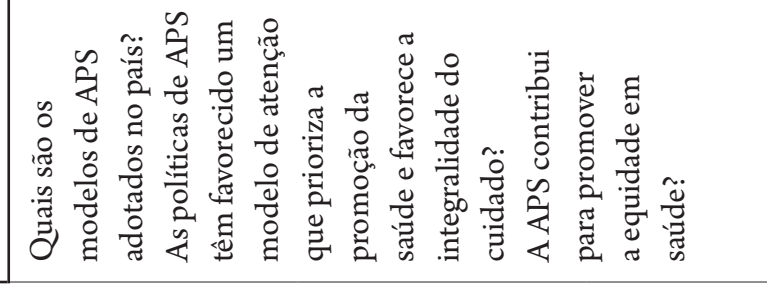 } \\
\hline
\end{tabular}




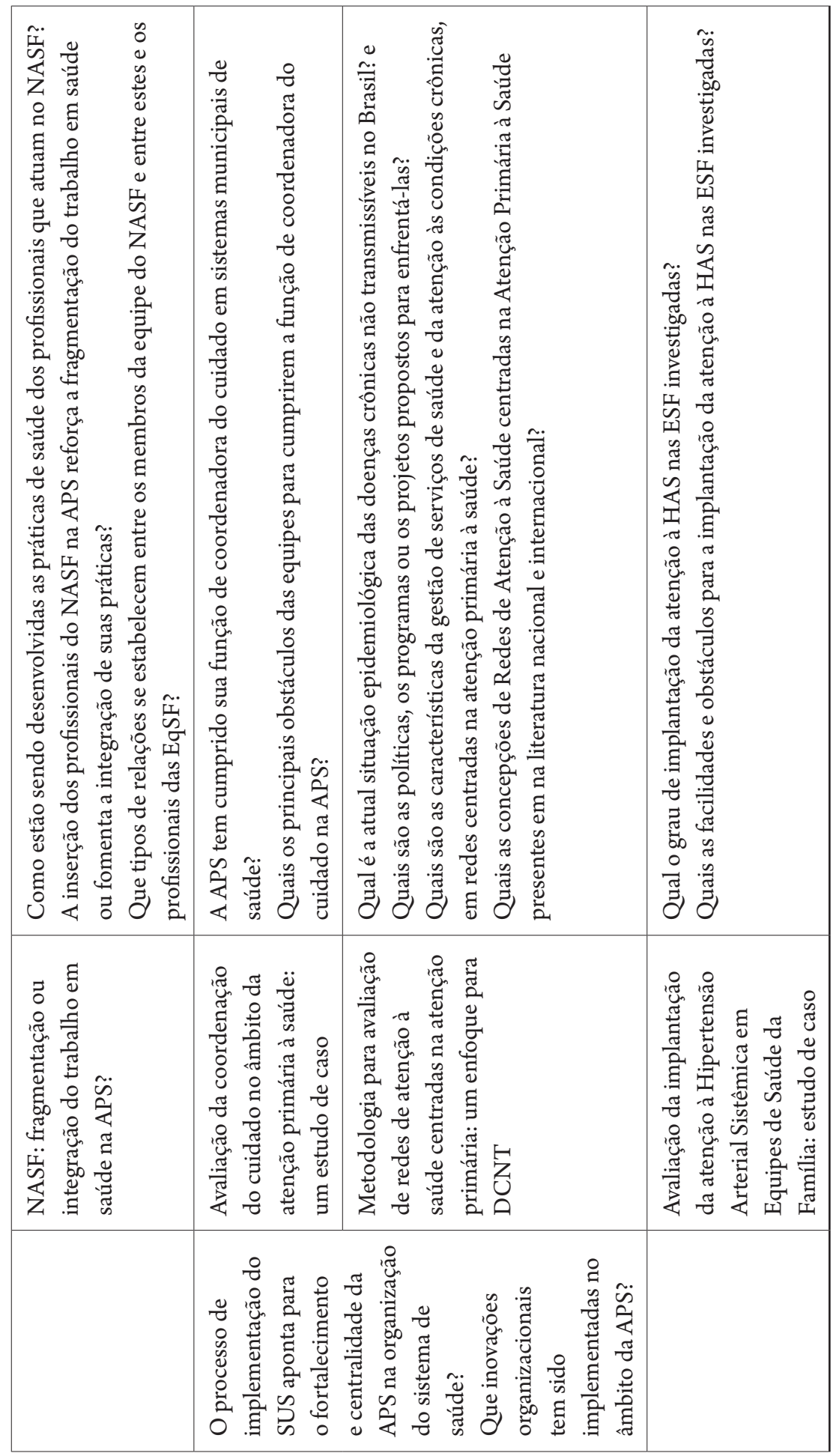

241






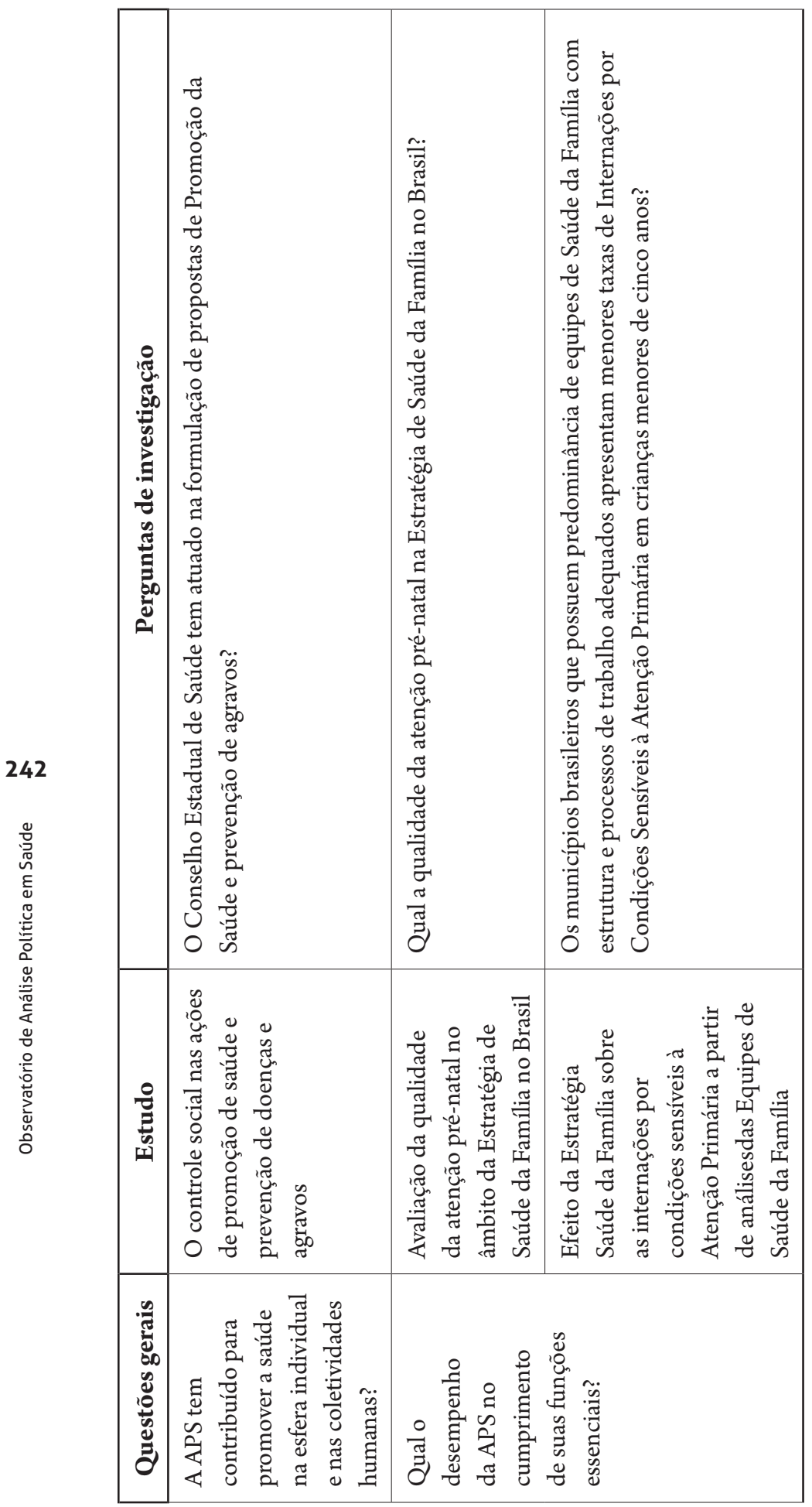






\section{Teorias e métodos na apreensão do objeto APS}

A APS, enquanto objeto de investigação, tem sido apropriada, pelo menos, em duas perspectivas analíticas: como prática ou como política. Em qualquer uma das perspectivas assinaladas, é possível abordá-las quanto ao seu "processo" ou quanto aos seus "resultados" ou efeitos. A experiência do nosso grupo de pesquisa tem sido a de realizar estudos que tratam de práticas de saúde na APS, de efetividade da política sobre determinados problemas de saúde da população e, mais recentemente, projetos de pesquisa que abordam a sociogênese da política de APS no Brasil, a formulação e implementação de políticas intersetoriais de promoção da saúde.

As duas perspectivas analíticas mencionadas, prática e política, têm se sustentado em referenciais de tradição sociológica (Marx, Bourdieu, Latour). No caso particular da produção científica latino -americana em Saúde Coletiva, destaca-se o uso das contribuições de Mendes-Gonçalves e Mário Testa, especialmente no que tange à apreensão de práticas de APS, tanto na dimensão técnica, propriamente dita, quanto na dimensão gerencial. Quanto à análise sócio -histórica das políticas de APS, é importante mencionar o trabalho de Pinell (2011), ancorado na sociologia bourdieusiana.

Quanto às práticas de APS, nos últimos 10 anos, destacam-se estudos (em sua maioria, dissertações de mestrado e teses de doutorado) sobreos agentes, suas relações sociais e técnicas, posições e disposições no espaço social (MEDINA, 2006; NUNES, 2011; SILVA, 2004); meios de trabalho empregados, atividades realizadas e racionalidades tecnológicas subjacentes (COSTA, 2009; SILVA, 2014); as relações entre o contexto e a implementação das práticas de APS em nível local. (MEDINA; HARTZ, 2009; VILASBÔAS; PAIM, 2008)

Parte desses estudos indicam que as escolhas teóricas dos autores partem do pressuposto que toda prática de saúde é histórica e socialmente determinada, e possui dimensão política para além de sua tecnicalidade. Essa perspectiva inspira-se nos estudos seminais 
sobre práticas de saúde da autoria de Cecília Donnângelo, continuados pelos pesquisadores do Departamento de Medicina Preventiva da Universidade de São Paulo (USP) (DONNANGELO, 1975, 1976; MENDES-GONÇALVES, 1992; SCHRAIBER, NEMES, MENDES-GONÇALVES, 2000; SCHRAIBER et al., 1999), de clara filiação marxista.

A produção de Mendes-Gonçalves sobre o processo de trabalho em saúde tem sido bastante utilizada nos estudos sobre práticas do Programa Saúde da Família (PSF). (COSTA, 2009; SILVA, 2004, 2014) Tal perspectiva teórica tem permitido um certo adensamento analítico em estudos exploratórios nos quais é possível caracterizar os objetos, meios de trabalho, finalidades e agentes das práticas investigadas e problematizar os limites do PSF quanto a possíveis mudanças na organização tecnológica do trabalho em APS.

Outro recorte proposto é o que permite investigar as práticas de gestão na APS. Nesse caso em particular, o Postulado de Coerência, proposição de autoria de Mario Testa (2004), foi utilizado em um 244 estudo sobre práticas de planejamento relacionadas à organização da atenção básica no âmbito municipal. Segundo o Postulado de Coerência, os propósitos de uma instituição, os métodos que utiliza para alcançá-los e a organização que assume devem ser coerentes. Há relações de determinação e condicionamento entre os três elementos do postulado, que, por sua vez, seriam sobre determinados pela história, pelo papel do Estado e pela teoria. A operacionalização das categorias analíticas do Postulado, em variáveis que compuseram a produção e análise dos dados empíricos, permitiu problematizar as relações interfederativas e ao interior da administração municipal que facilitaram ou restringiram a organização da APS no caso estudado. (VILASBÔAS; PAIM, 2008)

As investigações sobre efeitos do PSF sobre determinados problemas de saúde da população, a exemplo da mortalidade infantil, apresentam "sofisticação" metodológica e produção criativa de alternativas analíticas na realização de estudos ecológicos, com uso de dados secundários de sistemas oficiais de informação em saúde. 
(AQUINO; OLIVEIRA; BARRETO, 2008; RASELLA; AQUINO; BARRETO, 2010)

Estudos que buscaram interpretar as práticas de APS em função da posição e disposições dos agentes, a saber, profissionais de saúde atuantes em equipes de PSF e em coordenações municipais de atenção básica, fizeram-no a partir da sociologia reflexiva de Pierre Bourdieu. (MEDINA, 2006; NUNES, 2011) Esse referencial apresenta um conjunto de conceitos fundamentais - entre eles, habitus, campo, capital - empregados em estudos de diversas áreas, inclusive da saúde, com o intuito de entender os significados e conteúdo das práticas, em espaços sociais de saberes e disputas.

Bourdieu (2002) vê o espaço social como um campo de lutas onde os agentes (indivíduos e grupos) elaboram estratégias que permitem manter ou melhorar sua posição social. Essas estratégias estão relacionadas com os diferentes tipos de capital (simbólico, social, intelectual, cultural, econômico, político, militante e burocrático) (BOURDIEU, 1996), sendo importante compreender o significado de cada um dos capitais. O poder é uma resultante dessas diversas espécies de capital que se expressa na relação entre os agentes.

O referencial teórico de Bourdieu tem iluminado o estudo da gênese de políticas no campo da saúde. Para esse autor, a "amnésia da gênese", com o esquecimento das possibilidades que não se concretizaram, uma vez que foram derrotadas no curso das lutas políticas entre os agentes de um campo, precisa ser tomada como objeto de investigação e é um recurso metodológico importante no estudo de qualquer espaço social. (BOURDIEU, 2012)

Os estudos de Patrice Pinell (2011) sobre as políticas de aids, controle de drogas, e medicalização da falência escolar na França, nos séculos XIX e início do século XX, foram inovadores na aplicação da abordagem sócio-histórica às políticas de saúde e sustentaram a criação de uma linha de análise sócio histórica no Instituto de Saúde Coletiva (ISC), com estudos pioneiros como o de Barros (2013), que investigou a emergência do Programa de Incentivo Fiscal à Alimentação do Trabalhador, e o de Souza (2013), que analisou a 
gênese e consolidação da política nacional de controle da aids no Brasil. Essa é uma abordagem promissora, pelo seu potencial explicativo da determinação da gênese e consolidação do campo da APS, e vem muito recentemente, sendo adotada em alguns estudos.

Raros estudos no Brasil têm adotado a teoria do ator-rede na análise de práticas e políticas de atenção primária. No eixo APS, apenas um estudo adotou como referencial a teoria do ator-rede na análise de sustentabilidade do PSF em um município baiano. (OLIVEIRA, 2014) A utilização da teoria do ator-rede na análise da implementação do PSF em um município baiano trouxe como contribuição a realização de uma etnografia do Programa com detalhamento circunstanciado do seu processo de implementação, da dinâmica da intrincada rede de relações dos atores, e a identificação de fatores estratégicos que favoreceram a sustentabilidade do Programa ao longo do tempo. A nosso ver, a combinação de ferramentas desenvolvidas pela utilização dessa abordagem tem um potencial descritivo importante e pode ser combinada com referenciais mais robustos 246 para a compreensão de processos, especialmente na gestão de programas e intervenções no âmbito da APS.

A pouca utilização desse referencial na análise das práticas e políticas de APS contrasta com uma produção relativamente expressiva dessa abordagem em estudos brasileiros sobre promoção da saúde, vide, por exemplo, duas publicações em formato de livro que sistematizaram a utilização dessa teoria em pesquisas latino-americanas. (HARTZ; POTVIN; BODSTEIN, 2014; POTVIN; MCQUEEN, 2008) Registre-se que, em ambos os casos, houve parceria com a Universidade de Montreal, cujos pesquisadores são expoentes internacionais de linhas de investigação em promoção da saúde, vinculados a grupos de pesquisa de universidades brasileiras.

A teoria do ator-rede ou teoria da tradução é uma abordagem sociológica - sociologia das associações - desenvolvida, principalmente, por Bruno Latour (1994, 2006) e Michel Callon (1986, 2006) para a análise da dinâmica social, que enfatiza a conformação de redes sociotécnicas estabelecidas entre atores humanos e não 
humanos, portadores de interesses, e onde se constroem relações cuja intermediação exige um papel de tradução, desempenhado por porta-vozes das entidades ou agrupamentos (conjunto de atores). Latour (2006) critica a natureza social do social, rechaçando o determinismo como externalidade e o sujeito como agente (voluntarismo). Latour é reticente em relação à noção de grupo social. Para o autor, pertencer a um grupo é estar mobilizado por laços incertos, frágeis, controversos e constantemente flutuantes. Ao compreender que a ação [social] é, antes de tudo, surpresa, "alvo em movimento", sem causas ou consequências previsíveis, as abordagens que se baseiam em Latour tendem a ir de encontro a toda a tradição de análise política da Saúde Coletiva brasileira (pelo menos, da subárea de política, planejamento e gestão) e da tradição de pesquisa de grande parcela dos estudiosos da área.

Em que pese, entretanto, a existência de certa fragilidade teórica na explicação daquilo que determina uma ação social ou seu efeito, ao menos para quem se afilia a uma tradição não positivista de produção do conhecimento científico, há que considerar as contribuições dessa teoria no desenvolvimento de instrumentos que permitem descrever processos, especialmente na esfera da micropolítica, no espaço das relações interpessoais e da dinâmica do cotidiano, âmbitos pouco capturados por abordagens estruturalistas e, talvez, seja útil na compreensão dos obstáculos observados nas relações intersetoriais, cujas interfaces parecem exigir um verdadeiro trabalho de tradução de códigos de linguagem na definição de um possível interesse comum.

Ainda que seja uma apreciação preliminar, vale a pena problematizar algumas questões acerca do uso dos referenciais aqui apresentados. A produção dos pesquisadores indica um esforço de superar o senso-comum ou o senso douto acerca das dimensões assinaladas. Boa parte dos estudos apresentam pressupostos ou hipóteses derivados da construção teórica dos objetos de investigação que, por sua vez, sustentam as opções metodológicas na produção dos dados empíricos. Trata-se de um esforço analítico de des-naturalizar os 
processos de produção/desenvolvimento/realização de práticas ou de gênese/formulação/implementação de políticas de APS, isto é, de "objetivar" tais objetos.

A análise das posições e disposições dos agentes indicam hipóteses explicativas acerca das dificuldades na mudança da organização das práticas, em direção do ideal da integralidade, por exemplo. Ao mesmo tempo, o tratamento teórico dado ao contexto de implementação das práticas apresenta pistas para a interpretação das relações entre a micro e a macro política, ou entre sujeito e estrutura, indicando relações de condicionamento entre os agentes das práticas e o contexto político-institucional no qual as organizações se inserem, que podem restringir ou facilitar a realização de práticas de APS na perspectiva da Reforma Sanitária.

A adoção dos referenciais explicitados indica a filiação dos pesquisadores à Saúde Coletiva brasileira que, em parte, é espaço de produção de conhecimento científico objetivado e politicamente engajado na defesa do direito à saúde da população a ser assegura248 do pelo Estado. Esse posicionamento aumenta o compromisso dos pesquisadores com a qualidade acadêmica da investigação que, por ser a favor do interesse público, impõe a explicitação de suas opções teóricas e caminhos metodológicos.

\section{Cenário atual e sistematização de resultados da pesquisa em APS no Brasil}

A reforma do setor saúde que deu origem ao SUS e à atual forma de organização da APS no país ocorreu pari passu com o processo de democratização da sociedade brasileira e envolveu a participação de indivíduos e profissionais, de movimentos e organizações sociais. No momento atual, várias conquistas do movimento da reforma sanitária estão ameaçadas e o retrocesso a situações anteriores à década de 1990 é um horizonte que não pode ser descartado. A crise econômica e política brasileira, agudizada em 2016, com reforço às medidas de austeridade, restrição de recursos de financiamento global da 
saúde, resultado das pressões de lobistas e do setor privado, expressas em emendas constitucionais que foram e estão sendo objeto de votação do Congresso (como o orçamento impositivo e a Emenda Constitucional que prevê a expansão dos planos privados de saúde de baixa qualidade para todos os trabalhadores), a crise institucional no Executivo com substituição de gestores que representavam parcelas de movimentos sociais (como a coordenação de saúde mental e saúde bucal do Ministério da Saúde) e vários outros fatos recentes são expressão de mudanças que afetam profundamente os pilares sobre os quais o SUS foi construído.

O maior desafio, nesse contexto, é político e diz respeito à capacidade de mobilização da sociedade em prol da garantia do direito à saúde, articulado à defesa mais global da democracia e dos direitos humanos na sociedade brasileira. Reconhecer isso não é secundarizar as lutas específicas nem negar a importância de uma análise cuidadosa dos limites, impasses e possibilidades que conformaram o processo político de implementação das políticas de atenção primária à saúde no Brasil, na direção da construção de um sistema universal de saúde.

Aqui já se assume com menos reticência o vocábulo no plural políticas -, pois a trajetória da implementação da atenção primária à saúde no Brasil revela, por um lado, uma dinâmica de movimentos que traduz, possivelmente, visões diferentes da gestão no nível nacional em diferentes conjunturas históricas, diferenças da força de grupos de pressão que assumiram posição de destaque no cenário nacional e, por outro, um conjunto de iniciativas de diversas naturezas - financiamento, formação de pessoal, mecanismos de indução de preenchimento de vazios assistenciais, entre outros - que foram conformando e configurando os modelos de prestação de cuidados em contextos municipais marcados pela pluralidade e desigualdade.

Neste capítulo, não foi possível aprofundar tais questões. Para nós, empreender uma análise de base científica do processo político do desenvolvimento das políticas de APS em seus espaços (geral e singular), caracterizando os atores e interesses em jogo e as relações entre estes e a dinâmica do processo político mais global, é, ainda, 
uma tarefa a ser realizada, hoje, formulada como projeto prioritário de pesquisa desse eixo.

Do ponto de vista do desenho, pode-se afirmar que a ESF desenvolveu-se, nos últimos 20 anos, em direção a propostas de atenção primária à saúde integral e que, no discurso oficial, essa política tem sido apresentada como prioritária para a organização da APS e para a reorientação do modelo de atenção à saúde nas três esferas administrativas do SUS. (BRASIL, 1997a, 1997b, 2006, 2012)A distância entre discurso oficial, projeto expresso no texto das políticas, e a operacionalização de práticas organizacionais e assistenciais no âmbito dos serviços de APS e de sua articulação com o sistema de saúde são imensas. (MEDINA et al., 2014)

Os estudos em APS nos permitem realizar um balanço, sistematizados a seguir.

A expansão da cobertura e da utilização de serviços de APS no Brasil é fato incontestável. Ainda assim, permanecem problemas de acessibilidade, equidade e resolubilidade no cuidado prestado. 250 (ALVES et al., 2014; CASOTTI et al., 2014; FAUSTO et al., 2014; MENDES et al., 2014)

A APS tem demonstrado efetividade para lidar com um conjunto de problemas de saúde passíveis de resolução nesse âmbito, abarcando tanto condições agudas quanto crônicas. Algumas dessas conquistas são surpreendentes e mostram-se sinérgicas com outras políticas públicas, reforçando importância da articulação intersetorial nas intervenções mais globais para a conquista de melhor nível de saúde dos grupos populacionais. Entretanto, inúmeros problemas relacionados a escopo e qualidade da atenção permanecem, incluindo desde insuficiências na implementação de ações de prevenção e promoção da saúde até limitações na oferta e qualidade do cuidado prestado. Isso sem falar nas dificuldades relacionadas à coordenação do cuidado e articulação entre APS e demais serviços da rede, limitando a acessibilidade a outros níveis do sistema e, por conseguinte, a continuidade do cuidado. (ALMEIDA et al., 2010; ALVES et al., 2014; 
CASOTTI et al., 2014; FAUSTO et al., 2014; FONSECA et al., 2014; MENDES et al., 2014; MEDINA et al., 2014; RODRIGUES, 2014)

Se por um lado, tais limites, em parte, exigem respostas de natureza política, financeira, administrativa ou gerencial, por outro, na perspectiva da pesquisa, algumas questões não estão suficientemente respondidas.

No que diz respeito à promoção da saúde e intersetorialidade, o discurso retórico não tem instrumentalizado as equipes na condução de processos reais de articulação, devendo a pesquisa contribuir com o desenvolvimento e avaliação de estratégias que favoreçam a operacionalização de tais diretrizes. (AZEVEDO et al., 2012; ANDRADE, 2015; DIAS, 2014; MORETTI, 2010; RANTALA, 2014; TEIXEIRA; PAIM, 2000) Ressalva-se, entretanto, que ações sobre os determinantes desenvolvidas no âmbito da APS não podem ser levadas a cabo sem uma orquestração mais ampla que envolve políticas econômicas e sociais mais gerais, por exemplo, no âmbito da produção e distribuição de alimentos, de ocupação do espaço urbano, de enfrentamento da violência, entre outras.

251

Quanto às práticas de cuidado, aqui, como em diversos países do mundo, faltam ferramentas que auxiliem os profissionais nas decisões clínicas; alguns protocolos têm sido criticados pelo seu uso excessivamente normativo ou descontextualizado e pouco se tem estudado sobre as modificações que o uso de protocolos impõe na organização das práticas de cuidado. Assim cabe, também, à pesquisa, apoiar o desenvolvimento e avaliar a utilização de instrumentos inovadores pautados em evidências científicas, e seus efeitos, tanto na melhoria do cuidado quanto na organização dos processos de trabalho dos profissionais de saúde. (ALELUIA, 2014; RODRIGUES, 2014)

A pesquisa tem revelado a imensa heterogeneidade no país quanto à organização das práticas de cuidado e aos modelos de atenção, o que, de certa forma, é esperado dada a diversidade de contextos. Mas, também esses estudos têm demonstrado distanciamento dos "modelos observados" com os "modelos idealizados", mesmo em casos considerados exemplares no que diz respeito à implementação 
do SUS. (MEDINA; HARTZ, 2009; SANTOS, 2014; SOUZA, 2015) Isso significa que se mantém como desafio (permanente) da pesquisa a compreensão dos determinantes dos diferentes modelos e do insucesso ou sucesso na implementação das ações, assim como das novas configurações que surgem a partir dos novos arranjos e dos novos atores que entram em cena.

Finalmente, no que concerne à organização dos serviços, especialmente, de redes de atenção à saúde orientadas pela APS, a pesquisa tem revelado os limites nos processos de coordenação do cuidado (ALELUIA, 2014; ALMEIDA et al., 2010) e a necessidade de desenvolver tecnologias e propostas que permitam avaliar o desempenho dos serviços e de sua articulação, a efetividade das ações e as inovações que vão sendo construídas em processos singulares de organização e que, se estudadas, podem ser apropriadas em contextos semelhantes.

\section{Desafios e armadilhas da pesquisa em APS no Brasil}

Finalmente, gostaríamos de assinalar aqui alguns desafios de natureza epidemiológica, metodológica, epistemológica e ética que o trabalho de pesquisa em atenção primária evidenciam.

\section{Desafios conceituais e metodológicos}

Novos desafios epidemiológicos estão colocados com o crescimento das doenças crônicas no mundo, o desenvolvimento de novas ferramentas de cuidado e o avanço tecnológico. Há evidências na literatura de que a prevenção de doenças crônicas na APS exige a combinação de estratégias voltadas para a população em geral com a implementação de políticas regulatórias e controle ambiental capazes de contribuir com a redução desigualdades sociais - com abordagens individuais direcionadas para indivíduos com alto risco de doenças. Estas últimas, apesar de incapazes de produzir efeitos amplos em nível populacional, são efetivas para a prevenção de doenças nessa população. 
Os estudos mostram que as políticas globais, voltadas para a população em geral, são mais custo-efetivas e que uma pequena redução no risco global pode prevenir mais casos de doenças que tratar um pequeno número de pessoas com alto risco. Se isso é verdade, por outro lado, a população-alvo dos serviços de atenção primária tradicionalmente tem sido composta por indivíduos doentes ou que apresentam algum tipo de problema expresso em "sintomas". Em poucas experiências internacionais, e aí pode-se mencionar o Brasil como uma das exceções, a população em geral é, de fato, a população-alvo da APS.

Vale lembrar que os determinantes das causas não são os determinantes da incidência das doenças. E que uma intervenção sobre causas não utiliza das mesmas estratégias de uma intervenção sobre a doença.

Assim, seria possível dizer que o compromisso de uma APS efetiva e de qualidade - para além do cuidado primário em saúde - seria o de protagonizar ambas as estratégias de prevenção primária: estratégias que abordem globalmente a população e estratégias voltadas para a população de risco. Com grande ousadia, diríamos que o papel da APS seria o de coordená-las. Essa proposição se afina com um conceito ampliado de saúde e sublinha a necessidade de atuação sobre causas em vários níveis de determinação dos problemas de saúde - causas distais, intermediárias e proximais - e que conformam no Brasil um modelo de atenção denominado de modelo da vigilância da saúde.

$\mathrm{Na}$ experiência brasileira, as tentativas de articulação de atenção individualizada, atendendo às necessidades dos usuários, e políticas públicas mais globais, através de ações intersetoriais, são pouco expressivas e com algumas evidências de sucesso justamente onde se consegue operacionalizar o conceito de território.

A implantação de uma atenção primária territorializada viabiliza as oportunidades de encontro entre os profissionais e a população da área e favorece o estreitamento dos laços e a compreensão do contexto sociocultural e familiar no qual a equipe se insere.

A abordagem da APS, enquanto objeto complexo e multifacetado, traz desafios de natureza metodológica, especialmente relacio- 
nados a desenhos, indicadores e instrumentos de investigação. A defesa de uma perspectiva ampliada de saúde e de modelos de atenção inclusivos e integrais precisa ser acompanhada por formas de investigação e mensuração da realidade capazes de capturar inovações e transformações, o que não é possível com um elenco restrito de indicadores e instrumentos que foram desenvolvidos, principalmente, para descrever e analisar doenças, agravos e intervenções de forma descontextualizada.

A febre por publicação, resultados de sistemas de avaliação e fomento que estimulam a competitividade entre grupos de pesquisa e pesquisadores, tem tido consequências nefastas para a pesquisa com a reiteração daquilo que já se sabe. (CARVALHO; TRAVASSOS; COELI, 2013) É preciso arriscar mais e ter mais criatividade na criação de modelos de mensuração e avaliação que capturem as inovações. Macinko (2011) faz algumas sugestões nessa linha como a inclusão de componentes da APS em estudos de base populacional, a adaptação e utilização de instrumentos de vigilância, tais como

254 Internações por Condições Sensíveis à Atenção Primária (ICSAP), no âmbito da APS, o investimento em inquéritos específicos em atenção primária e o uso de métodos experimentais para testar inovações.

\section{Desafios epistemológicos e éticos}

O espaço social da APS é marcado por disputas de natureza política e ideológica entre atores, cujos interesses se manifestam e se traduzem no campo científico. Isso não é particular a esse espaço social. Compreender quais são essas disputas e interesses e os mecanismos pelos quais elas produzem efeitos no campo científico é imperativo.

Nessa seara, nos parece que uma das questões relevantes é o dilema entre imposição de problemática versus absenteísmo político. Como mencionamos anteriormente neste capítulo, a pesquisa em atenção primária é subfinanciada e grande parte dos recursos destinados a ela provêm de fontes ligadas ao Governo Federal, impondo uma agenda de pesquisa afinada com seus propósitos de implemen- 
tação de políticas. Configura-se, assim, uma "imposição de problemática” (BOURDIEU, 2002) em relação à qual é necessária uma vigilância epistemológica.

Ceder à imposição de problemática é estudar apenas o que se coloca como relevante pelas instituições do Estado e de financiamento da pesquisa. Limitar a agenda de grupos de pesquisa à problemática do governo, especialmente em circunstâncias onde recursos são escassos e a luta pela sobrevivência desses grupos está na ordem do dia, traz consigo grandes riscos e exige vigilância redobrada. Vale a pena ressaltar que temáticas por vezes triviais podem revelar e contribuir muito mais com a produção do conhecimento científico do que problemas tidos como prioritários. Estes, muitas vezes, são problemas de gestão ou da prática cotidiana dos serviços, travestidos de problemas de pesquisa.

Para compreender a sociedade francesa de seu tempo, os mecanismos de reprodução das desigualdades e de dominação, Bourdieu (2007) precisou estudar a arte, a fotografia e o esporte e elaborou uma teoria muito fecunda sobre a ação social. Para dar um exemplo mais próximo à nossa realidade, a tese de Arouca (1975), o dilema preventivista, marco da constituição do campo da Saúde Coletiva brasileira, não surgiu de uma demanda institucional, governamental, mas do incômodo essencial do pesquisador na busca da compreensão de fenômenos contemporâneos. Foi defendida na surdina, quase clandestinamente, sem audiência.

Assim, postulamos que um dos desafios da pesquisa em APS, e mesmo na temática geral de política, planejamento e gestão em saúde, é a garantia do grau de autonomia e distanciamento necessários à produção de um conhecimento relevante, seja recolocando ou promovendo a releitura das questões postas pelo Estado através das instituições e seus atores (gestores e profissionais) e pela sociedade, através dos grupos sociais e suas representações, seja trazendo para o escopo das preocupações de pesquisa questões que, na sua aparência, são desinteressantes na perspectiva de uma solução imediata para os problemas da atualidade. 
Isso não deve significar, entretanto, adotar o absenteísmo político como máxima da prática de pesquisa. $\mathrm{O}$ contraponto do risco da imposição de problemática (BOURDIEU, 2002) é o absenteísmo político, uma forma de alienação intelectual (BURAWOY, 2010), que significa a realização de uma pesquisa asséptica, distanciada e avessa aos problemas da contemporaneidade e de suas soluções; arredia ao compromisso social de produção intelectual relevante para a sociedade e de uma prática política que lhe seja consequente. Uma pesquisa que não quer e não pretende comunicar, que não ousa estabelecer relações de solidariedade com a sociedade, que pensa o "pensar" como atividade nobre e o fazer como atividade espontânea, que não se preocupa em "transformar" nem a sociedade, nem os sujeitos, muito menos a si própria. E por isso não é capaz de trazer uma contribuição relevante ao mundo social que a acolhe a sustenta.

Em se tratando de um espaço de lutas políticas e ideológicas, enfrentar o risco de submissão ao senso comum e ao senso comum douto, ou seja, de sucumbir ao pré-conceito, é também um desafio que se coloca no plano da ética. É necessário ter cuidado para que a filiação a uma escola de pensamento não se transforme em ideologia acadêmica e que a luta (fértil) de ideias não se transforme, exclusivamente, em disputa de prestígio e de espaços de poder no seio das instituições, sejam elas acadêmicas ou de serviços. Essa armadilha é tão nociva à Academia quanto ao SUS, pois tem como resultado a perda do rigor científico e a produção de uma "pesquisa panfletária" que desconhece a própria história da produção de conhecimento em um determinando ponto da história. Nesse ponto, se é possível ser complacente com militantes gestores, usuários e alunos, pegos por esse tipo de armadilha, o pesquisador, além de defender enquanto militante o seu projeto ético-político de sociedade, deve ter, pensamos nós, o compromisso militante de preservar a história dos conceitos, a constituição genética de suas origens, sua aplicação científica e o justo valor de sua contribuição social. 


\section{Referências}

ANDRADE, L. O. M. et al. Social determinants of health, universal health coverage, and sustainable development: case studies from. Latin American countries, [S.I.] v. 385, n. 9975, p. 1343-1351, Apr. 2015.

AQUINO, R.; OLIVEIRA N. F. de; BARRETO M. L. Impact of the family health program on infant mortality in Brazilian municipalities. American Journal of Public Health, New York, v. 99, p. 87-93, 2008.

AQUINO, R. et al. Estratégia saúde da família e o reordenamento do sistema de serviços de saúde. In: PAIM, J. S.; ALMEIDA-FILHO, N. de. (Org.). Saúde coletiva:teoria e prática. 1. ed. Rio de Janeiro: Medbook, 2014. p. 3-695. v. 1.

ALELUIA, I. R. S. Avaliação da coordenação do cuidado no âmbito da atenção primária à saúde: um estudo de caso. 2014. 115 f. Dissertação (Mestrado em Saúde Comunitária) - Instituto de Saúde Coletiva, UFBA. Salvador. 2014.

ALVES, M. G. M. et al. Fatores condicionantes para o acesso às equipes da Estratégia Saúde da Família no Brasil. Saúde em debate, Rio de Janeiro, v. 38, p. 34-51, 2014. Edição especial.

ALMEIDA, P. F. et al. Desafios à coordenação dos cuidados em saúde: estratégias de integração entre níveis assistenciais em grandes centros urbanos. Caderno Saúde Pública, Rio de Janeiro, n. 26, v. 2, p. 286-298, 2010 .

AROUCA, A. S. S. O dilema preventivista: contribuição para a compreensão e crítica da medicina preventiva. 1975. 197 f. Tese(Doutorado de Ciências Médicas) - Faculdade de Ciências Médicas, Universidade Estadual de Campinas, 1975.

AZEVEDO, E.; PELICIONE, M. C. F; WESTPAL, M. F. Práticas intersetoriais nas políticas públicas de promoção de saúde. Revista de Saúde Coletiva, Rio de Janeiro, v. 22, n. 4, p. 1333-1356, 2012.

BARROS S. G. A política nacional de luta contra a aids e o espaço aids no Brasil. 2013. 274 f. Tese (Doutorado em Saúde Pública) - Instituto de Saúde Coletiva, Universidade Federal da Bahia, Salvador, 2013. 
BRASIL. Ministério da Saúde. Política Nacional de Atenção Básica. Brasília, DF: 2012. (Série E. Legislação em Saúde)

BRASIL. Ministério da Saúde. Secretaria de Atenção à Saúde.

Departamento de Atenção Básica. Política nacional de atenção básica Brasília, DF, 2006.

BRASIL. Ministério da Saúde. Norma Operacional Básica do Sistema Único de Saúde/SUS. Brasília, DF, 1997a.

BRASIL. Ministério da Saúde. Saúde da Família: uma estratégia para a reorientação do modelo assistencial. Brasília, DF, 1997b.

BOURDIEU, P. Campo de poder, campo intelectual e habitus de classe. In: BOURDIEU, P. Economia das trocas simbólicas. Rio de Janeiro: perspectiva, 1992. p. 201-220.

BOURDIEU, P. Razões práticas: sobre a teoria da ação. Tradução de Mariza Corrêa. Campinas: Papirus, 1996.

BOURDIEU, P. A distinção: crítica social do julgamento. Porto Alegre: Zouk, 2007.

BOURDIEU, P. O poder simbólico. Rio de Janeiro: Bertrand Brasil, 2002.

BOURDIEU, P. Sur l'État: cours au Collège de France 1989-1992. Paris: Éditions Raisons d'agir Éditions Seuil, 2012.

BOURDIEU, P. A ordem do discurso: aula inaugural no College de France, pronunciada em 2 de dezembro de 1970. 5.e d. São Paulo: Loyola, 1999.

BURAWOY, M. O marxismo encontra Bourdieu. Tradução de Fernando Rogério Jardim. Campinas: Editora da UNICAMP, 2010.

CALLON, M. Éléments pour une sociologie de la traduction. L'année sociologique,[S.1.], n. 36, p. 169-208, 1986.

CALLON, M. Quatre modeles pour decrire la dynamique de la science. In: AKRICH, M; CALLON, M.; LATOUR, B. Sociologie de la traduction: textes fondateurs. Paris: PressesMines, 2006. p. 201-252.

CARVALHO, M. S.; TRAVASSOS, C., COELI, C.M. More ofthesameepidemiology? Caderno Saúde Pública, Rio de Janeiro, v. 29, n. 11, p. 2141-2143, 2013. 
CASOTTI, E. et al. Atenção em Saúde Bucal no Brasil: uma análise a partir da Avaliação Externa do PMAQ-AB. Saúde em debate, Rio de Janeiro, v. 38, p. 140-157, 2014. Edição especial.

CARVALHO, S. C.; MOTA, E.; DOURADO, I.; AQUINO, R.; TELES, C., MEDINA, M. G. Hospitalizations of children due to primary health care sensitive conditions in Pernambuco State, Northeast Brazil. Caderno de Saúde Pública, Rio de Janeiro, v. 31, n. 4, p. 744-754, 2015.

COSTA, J. G. O modo tecnológico da vigilância à saúde e o trabalho das equipes de Saúde da Familia. 2009. 132 f.Dissertação (Mestrado em Saúde Comunitária) - Instituto de Saúde Coletiva, Universidade Federal da Bahia, Salvador, 2009.

DELANEY, B. Primary care research in the postmodern world. Family Practice, Oxford, v. 21, n. 2, p. 123-124, 2004.

DIAS, M. S. A. et al. Intersetorialidade e estratégia saúde da família: tudo ou quase nada a ver? Ciência \& Saúde Coletiva, Rio de Janeiro, v.19, n. 11, p. 4371-4382, 2014.

DONNANGELO M. C.; PEREIRA, L. Saúde e sociedade. São Paulo:

Duas Cidades; 1976.

DONNANGELO, M. C. F. Medicina e sociedade: o médico e seu mercado de trabalho. São Paulo: Pioneira, 1975.

DOUGLAS, J. D. M. Is primary care research a lost cause [lette]? Lancet, London, n. 361, p. 1473-1474, 2003.

DOURADO, I. et al. Trends in primary health care sensitive conditions in Brazil: the role of the Family Health Program (Project ICSAP-Brazil). Medical Care, Philadelphia,v. 49, n. 6, p. 579-584, 2011.

FACCHINI, L. A. et al. Desempenho do PSF no Sul e no Nordeste do Brasil: avaliação institucional e epidemiológica da Atenção Básica à Saúde. Ciência Saúde Coletiva, Rio de Janeiro, v. 11, n. 3, p. 669-681, 2006.

FAUSTO, M. C. R. et al. A posição da Estratégia Saúde da Família na rede de atenção à saúde na perspectiva das equipes e usuários participantes do PMAQ-AB. Rio de Janeiro, v. 38, n. especial, p. 13-33, 2014. 
FONSECA SOBRINHO, D. et al. Compreendendo o apoio matricial e o resultado da certificação de qualidade nas áreas de atenção à criança, mulher, diabetes/hipertensão e saúde mental. Saúde em debate, Rio de Janeiro, v. 38, p. 83-93, 2014. Edição especial.

GROL, R.; JONES, R. Twenty years of implementation research. Family Practice, Oxford, v. 17, p. 32-35, p. 2000.

HARTZ, Z.; POTVIN, L.; BODSTEIN, R. (Org.). Avaliação em promoção da saúde: uma antologia comentada da parceria entre o Brasil e a Cátedra de Abordagens Comunitárias e Iniquidades em Saúde (CACIS), da Universidade de Montreal de 2002 a 2012. Brasília, DF: CONASS, 2014.

HOWE, A. Isprimary care research a lost cause [letter]? Lancet, London, v. 361, p. 1473-1474, 2003.

HUMMERS-PRADIER, E., et al. Research agenda for general practice / family medicine and primary health care in Europe.Maastricht: WONCA Europe, 2009. LATOUR, B. Jamais fomos modernos. Rio de Janeiro: Nova fronteira, 1994.

LATOUR, B. Changer de societé: refaire de la sociologie. Paris: la découverte, 2006.

MACIEL, A. G.; CALDEIRA, A. P.; DINIZ, F. J. P. S. Impacto da Estratégia Saúde da Família sobre o perfil de morbidade hospitalar em Minas Gerais. Saúde em Debate. Rio de Janeiro, v. 38, p. 319-330, 2014. Edição especial.

MACINKO J.; DOURADO I.; GUANAIS, F. C. Chronic diseases, primary care and health systems performance diagnostics, tools and interventions. [S.1.]: Inter-American Development Bank, 2011.

MACINKO, J.; ALMEIDA, C. Validação de uma metodologia de avaliação rápida das características organizacionais e do desempenho dos serviços de atenção básica do sistema de saúde (SUS) em nível local. Brasília, DF: Organização Panamericana da Saúde, 2006. (Série técnica desenvolvimento de sistemas e serviços de saúde, 10). 
MACINKO, J. et al. Going to scale with community-based primary care: An analysis of the family health program and infant mortality in Brazil, 1999-2004. Social Science \& Medicine, [S.I.] p. 2070-2080, 2007.

MACINKO, J et al. Organization and delivery of primary health care services in Petrópolis, Brazil. The International Journal of Health Planning and Management, Chichester,v. 19, n. 4, p. 303-317, 2004.

MCAVOY, B. R. Primary care research: what in the world is going on? The Medical Journal of Australia, Sydney, v. 182, n. 32, p. 110-112, 2005.

MENDES- GONÇALVES,R. B. Práticas de saúde: processos de trabalho e necessidades. São Paulo: CEFOR, 1992.

MENDES-GONÇALVES, R. B. Tecnologia e organização social das práticas de saúde: características tecnológicas do processo de trabalho na rede estadual de centros de saúde de São Paulo. São Paulo: Hucitec: Abrasco, 1994.

MENDES, L. V. et al. Disponibilidade de medicamentos nas unidades básicas de saúde e fatores relacionados: uma abordagem transversal. Saúde em debate, Rio de Janeiro, v. 38, p. 109-123, 2014. Edição especial.

MEDINA, M. G. O contexto local, a organização da atenção primária e a implementação de redes integradas de atenção à saúde: resultados da avaliação de dois estudos de caso. 2006. $261 \mathrm{f}$. Tese (Doutorado em Saúde Pública) - Instituto de Saúde Coletiva, Universidade Federal da Bahia, Salvador, 2006.

MEDINA, M. G; HARTZ, Z. M. A. The role of the Family Health Program in the organization of primary care in municipal health systems. Caderno de Saúde Pública, Rio de Janeiro, v. 25, n. 5, p. 1153-1167, 2009.

MEDINA M. G. et al. Promoção da saúde e prevenção de doenças crônicas: o que fazem as equipes de Saúde da Família? Saúde Debate, Rio De Janeiro, v. 38, p. 69-82, 2014. Edição especial.

MORETTI, A. C. Intersetorialidade nas ações de promoção de saúde realizadas pelas equipes de saúde bucal de Curitiba (PR). Ciência \& Saúde Coletiva, Rio de Janeiro, v.15, n. 1, p. 1827-1834, 2010. Suplememento. 
NEDEL, B. et al. Conceptual and methodological aspects in the study of hospitalizations for ambulatory care sensitive conditions. Ciência \& Saúde Coletiva, Rio de Janeiro, v. 16, p. 1145-1154, 2011.

NUNES, C. A. A integralidadeda atenção e o programa de saúde da família: estudo de caso em um município do interior da Bahia. 2011. $192 \mathrm{f}$. Tese (Doutorado em Saúde Pública) - Instituto de Saúde Coletiva, Universidade Federal da Bahia, Salvador, 2011.

NUNES, C. A. et al. Avaliação do perfil dos agentes comunitários de saúde (ACS) no processo de consolidação da atenção primária à saúde no Brasil: tomo 2 - Práticas dos ACS. Salvador: Instituto de Saúde Coletiva, Universidade Federal da Bahia, 2015.(Relatório Preliminar de Projeto de pesquisa).

OLIVEIRA, S. R. A. Sustentabilidade da estratégia saúde da familia: o caso de um município baiano. 2014.143 f. Tese (Doutorado em Saúde Pública) - Instituto de Saúde Coletiva. Universidade Federal da Bahia, Salvador, 2014.

ORGANIZACIÓN PANAMERICANA DE SALUD - OPAS. Renovação da Atenção Primária nas Américas: documento de posicionamento da Organização Panamericana de Saúde/Organização Mundial de Saúde (OPAS/OMS). Washington, 2007.

PAIM, J. S.; TEIXEIRA, C. F. Política, planejamento e gestão em saúde: balanço do estado da arte. Revista de Saúde Pública, Rio de janeiro, v. 40, p. 73-78, 2006.

PEDUZZI, M. Mudanças tecnológicas e seu impacto no processo de trabalho em saúde. Trabalho, Educação e Saúde, Rio de Janeiro, v. 1, n. 1, p. 75-91, 2003.

PEREIRA, F. J. R.; SILVA, C. C.; NETO, E. A. L. Condições sensíveis à atenção primária:uma revisão descritiva dos resultados da produção acadêmica brasileira. Saúde em Debate, Rio de Janeiro, v. 38, p. 331-342, 2014. Edição especial.

PINELL, P. Análise Sociológica das políticas de saúde. Rio de Janeiro: Fiocruz, 2011. 
PICCINI, R. X. et al. Necessidades de saúde comuns aos idosos: efetividade na oferta e utilização em atenção básica à saúde, Ciência e Saúde Coletiva, Rio de Janeiro, v. 11, n. 3, p. 657-667, 2006.

POTVIN, L.; MCQUEEN, D. Health promotion evaluation in the Americas: values and research.New York: Springer, 2008.

RANTALA, R. et al. Intersectoral action: local governments promoting health. Health Promotion International, Oxford, v. 29, n. 1, 2014.

RASELLA, D.; AQUINO, R.; BARRETO, M. L. Impact of the family health program on the quality of vital information and reduction of child unattended deaths in Brazil: an ecological longitudinal study. BMC Public Health, London, v. 10, n. 380, p. 1-8, 2010.

RASELLA, D. et al. Impact of primary health care on mortality from heart and cerebrovascular diseases in Brazil: a nationwide analysis of longitudinal data. BMJ, [S.1.], v. 3, n. 349, p. 1-10, 2014.

RASELLA, D. et al. Effect of a conditional cash transfer programme on childhood mortality: a nationwide analysis of Brazilian municipalities. The lancet, Londom,v. 382, n. 9886, p. 57-64, July 2013.

RODRIGUES-BASTOS, R. M. et al. Internações por condições sensíveis à atenção primária, Minas Gerais, 2000 e 2010. Revista Saúde Pública, Rio de Janeiro, v. 48, n. 6, p. 958-967, 2014.

RODRIGUES, F. F. Avaliação dos serviços farmacêuticos na atenção primária à saúde no cuidado ao paciente com tuberculose em unidades de saúde do município de Salvador-BA. 2014. 136 f. Dissertação Mestrado (Mestrado em Saúde Comunitária) - Instituto de Saúde Coletiva, Universidade Federal da Bahia, Salvador, 2014.

ROSANO, A. The relationship between avoidable hospitalization and accessibility to primary care: a systematic review. European Journal of Public Health, Oxford, v. 23, n. 3, p. 356-360, 2012.

SCHRAIBER, L. B.; NEMES, M. I. B.; MENDES-GONÇALVES, R. B. (Org.). Saúde do adulto: programas e ações na unidade básica. 2. ed. São Paulo: Hucitec, 2000. 
SCHRAIBER L. B. et al. Planejamento, gestão e avaliação em saúde: identificando problemas. Ciência Saúde Coletiva, Rio de Janeiro, v. 4, n. 2, p. 221-242, 1999.

SANTANA, M.; AQUINO, R.; MEDINA, M. G. Efeito da Estratégia Saúde da Família na vigilância de óbitos infantis. Revista de Saúde Pública, São Paulo, v. 46, n. 1, p. 59-67, 2012.

SANTOS L. T. S. O controle social nas ações de promoção da saúde e prevenção de doenças e agravos. 2014. 82 f. Dissertação (Mestrado em Saúde Comunitária) - Instituto de Saúde Coletiva, Universidade Federal da Bahia, Salvador, 2014.

SOUZA, J. C. A gênese do programa de incentivo fiscal à alimentação do trabalhador (PIFAT/PAT). 2013. 261 f. Tese (Doutorado em Saúde Pública) - Universidade Federal da Bahia, Instituto de Saúde Coletiva, Salvador, 2013.

SILVA, V. C. Avaliação da implantação da atenção à hipertensão arterial sistêmica em unidades de saúde da familia: estudo de caso. 2014. $131 \mathrm{f}$. Dissertação (Mestrado em Saúde Comunitária) - Instituto de Saúde Coletiva, Universidade Federal da Bahia, Salvador, 2014.

SILVA, I. Z. Q.J. Equipe de saúde da família: problematizando a articulação técnica e a interação entre profissionais. 2004. Dissertação (Mestrado em Saúde Comunitária) - Instituto de Saúde Coletiva, Universidade Federal da Bahia, Salvador, 2004.

STARFIELD, B. Measuring the attainment of primary care. Medical Education, Oxford, v. 54, n. 5, p. 361-369, 1979.

STARFIELD, B. Atenção primária à saúde: equilíbrio entre a necessidade de saúde, serviços e tecnologias. Brasília, DF: UNESCO: Ministério da Saúde, 2002.

SOUZA, T. S. NASF: fragmentação ou integração do trabalho em APS? 2015. 149 f. Dissertação (Mestrado em Saúde Comunitária) - Instituto de Saúde Coletiva, Universidade Federal da Bahia, Salvador, 2015.

SPEDO, S. M; TANAKA, O. Y.; PINTO, N. R. S. O desafio da descentralização do Sistema Único de Saúde em município de grande 
porte: o caso de São Paulo, Brasil. Caderno de Saúde Pública, Rio de Janeiro, v. 25, n. 8, p. 1781-1790, ago. 2009.

TEIXEIRA, C.; PAIM, J. Planejamento e programação de ações intersetoriais para a promoção da saúde e da qualidade de vida. Revista de Administração Pública, Rio de Janeiro, v. 3, n. 6, p. 63-80, nov./dez, 2000.

TESTA, M. Pensar em salud. $3^{\text {a }}$ ed. Buenos Aires: Lugar Editorial, 2004.

TOMASI, E. et al. Características da utilização de serviços de atenção básica à saúde nas regiões Sul e Nordeste do Brasil: diferenças por modelo de atenção. Ciência de Saúde Coletiva, Rio de Janeira, v. 16, n. 11, p. 4395-4404, nov. 2011.

TOMASI, E. et al. Estrutura e processo de trabalho na prevenção do câncer do colo de útero na atenção básica à saúde no Brasil: Programa de Melhoria do Acesso e da Qualidade PMAQ. Revista Brasileira de Saúde Materno Infantil, Recife, v, 15, n. 2, p. 171-180, abr./jun. 2015.

VIACAVA, F. et al. Uma metodologia de avaliação do desempenho do sistema de saúde brasileiro. Ciência \& Saúde Coletiva, Rio de Janeiro, v. 9, n. 3, p. 711-724, 2004.

VILASBÔAS, A. L. Q.; PAIM, J. S. Práticas de planejamento e implementação de políticas no âmbito municipal. Caderno Saúde Pública, Rio de Janeiro, v. 24, n. 6, p. 1239-1250, 2008.

VIEIRA-DA-SILVA L. M.; PINELL, P. The genesisofcollectivehealth in Brazil. Sociology of health \& Illness, Oxford, v. 36, n. 3, p. 432-46, 2014.

WONCA EUROPA. A definição européia de medicina geral e familiar: (clínica geral/medicina familiar). [S.l.], 2002. 